\title{
Case Study on the Comparison of the Performance between Chinese and American High-tech Companies: Apple Inc.\& Huawei Technologies
}

\author{
Lan Zhang ${ }^{1, a}$, Zixuan Wang ${ }^{2, b}$ Ao Zhang ${ }^{3, c,{ }^{*} \text { Dongkun Song }}$, d \\ ${ }^{1}$ School of Accounting, Jilin University of Finance and Economics, Changchun, China \\ ${ }^{2}$ School of International, Jilin University of Finance and Economics, Changchun, China \\ ${ }^{3}$ School of Accounting, Jilin University of Finance and Economics, Changchun, China \\ ${ }^{4}$ School of Public Administration, Jilin University of Finance and Economics, Chang- chun, China \\ azhanglan_win@163.com, ${ }^{\mathrm{b}} \mathrm{m} 13904396307 @ 163 . c o m,{ }^{\mathrm{c}}$ zhangao0622@sina.com, \\ d1176364470@qq.com
}

Keywords: High-tech companies, Performance difference, Performance evaluation.

\begin{abstract}
The performance comparison of high-tech companies is drawn from the differences between enterprise performance in domestic and foreign culture. As the advanced enterprise management, performance management of high-tech companies has been technically mature in foreign countries. By analyzing the differences of corporate culture and technological performance at home and abroad, we compared the differences of performance management between two large-scale technology mobile phone companies of Apple Inc. and Huawei Technologies. The main contribution of this paper is to provide better reference for the performance management of domestic high-tech companies.
\end{abstract}

\section{Introduction}

With the rapid development of science and technology, the companies are facing more and more competition and tests. To improve the positions of the companies in the market, performance management is essential to see how the innovation ability of companies can progress in the internationalization. The companies will make progress after the comparison every time. Enterprise performance refers to the enterprise's operating efficiency and operator's performance in a certain period of the operation ${ }^{[1]}$. For high-tech companies, technological innovation means the improvement of performance. Therefore, we choose two representative technology companies at home and abroad, Huawei Technologies in China and Apple Inc. in the United States to compare the different performance effects brought by the technology effects of the two companies.

Performance management is a part of enterprise management. We can see the difference of performance management from different companies at home and abroad. Today, the development of science and technology in China has strong momentum, but the outstanding performance is the disconnection between science and technology and economy ${ }^{[2]}$. With the continuous development of high-tech technology, technology has also been brought into our lives, which facilitates our lives. China has put the development of high-tech industries at the national level.

\section{Case Presentation}

\subsection{Company Profile}

\subsubsection{Apple Inc.}

Apple Inc. went public on December 12, 1980, setting a market value record of $\$ 623.5$ billion in 2012. As of June 2014, Apple Inc. has become the world largest company by market value for three consecutive years. Apple Inc. was founded on January 3, 1977, with its headquarters in Cupertino, California. On December 12, 1980, Apple Inc. was listed on the Nasdaq Stock Exchange (AAPL) in the United States. The company is mainly engaged in the design, production and marketing of 
mobile communication and media equipment. Its products are mainly aimed at the most education consumers, businesses and government users.On September 30, 2013, in the "global best brand" report of Hongmeng group, Apple Inc. surpassed Coca Cola to become the most valuable brand in the world. In 2014, Apple Inc. surpassed Google as the world's most valuable brand. Apple Inc. ranked 9th in the 2016 world top 500 companies which famous all over the world. Apple Inc.'s performance management uses balanced scorecard to evaluate and enhance corporate performance. 2.1.2 Huawei Technologies

Huawei Technologies is a private communication technology company that produces and sells communication equipment. Founded in Shenzhen in 1987, with a sales volume of 1.5 billion yuan in 1995, it mainly comes from China's rural market. In 1998, it expanded its market to China's major cities and opened up overseas markets in 1999. In 2005, the overseas contract sales exceeded the domestic contract sales for the first time. In 2008, it was rated as the world's top ten most influential companies by the business week. In 2009, its wireless access market share ranked the first in the world. In 2013, it has entered more than 100 capital cities around the world, covering nine financial centers.

\subsection{Performance Comparison}

In order to compare the performance of Huawei Technologies and Apple Inc. more comprehensively, the profit indicators of the two companies in the past five years are compared. The data comes from the annual report of Apple Inc. and the publicly disclosed data of Huawei Technologies, as shown in Table 1 and Table 2.

Table 1. The Profit Index of Apple Inc.

\begin{tabular}{cccccc}
\hline Year & 2013 & 2014 & 2015 & 2016 & 2017 \\
\hline Revenue & 170910.00 & 182795.00 & 233715.00 & 215639.00 & 229234.00 \\
\hline Gross profit & 64304.00 & 70537.00 & 89027.00 & 82720.00 & 86870.00 \\
\hline Net profit & 37037.00 & 59713.00 & 53394.00 & 45680.00 & 48351.00 \\
\hline
\end{tabular}

Table 2. The Profit Index of Huawei Technologies

\begin{tabular}{cccccc}
\hline Year & 2013 & 2014 & 2015 & 2016 & 2017 \\
\hline Sales revenue & 239052.0 & 288197 & 3950.09 & 5215.74 & 6030 \\
\hline Operating activities cash flows & 225.54 & 417.55 & 493.15 & 492.18 & 963 \\
\hline Net profit & 21003 & 27866 & 26910 & 37052 & 47500 \\
\hline
\end{tabular}

Then we present the profits of the two companies in the same line chart to compare the performance differences between them more clearly as shown in Figure 1.

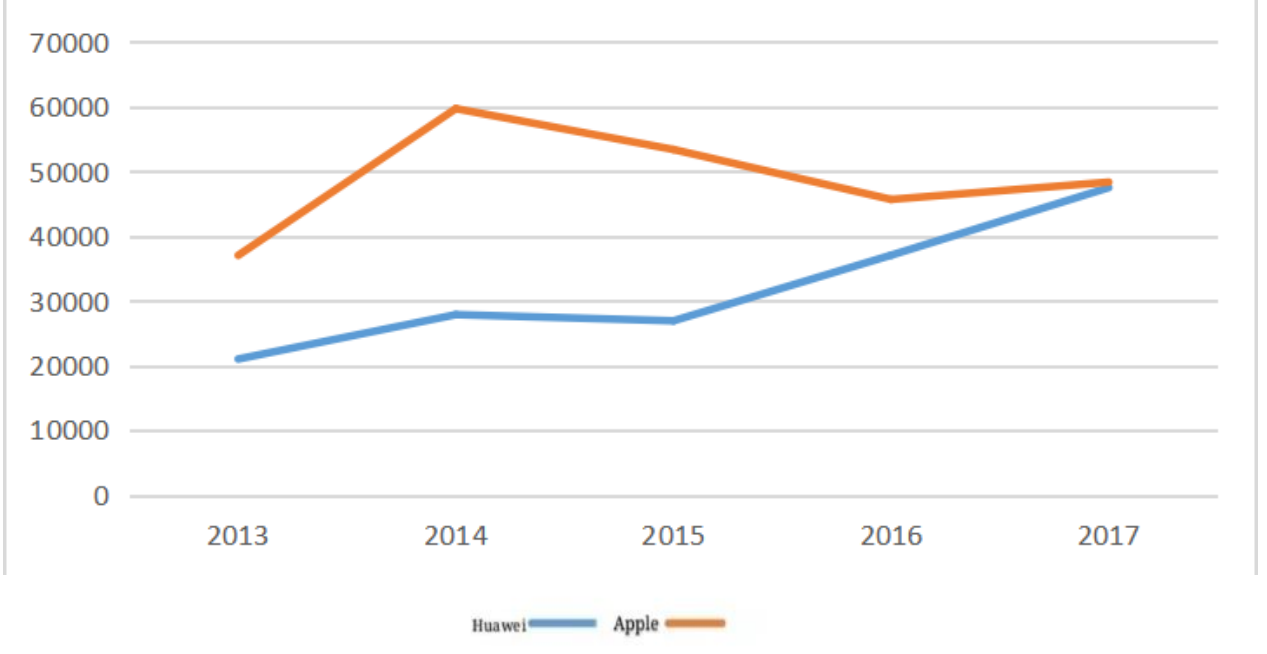

Fig. 1. The Profit of Apple Inc. and Huawei Technologies

It can be found that the profit margin in the past five years is very stable. For the income statement, the overall operating interest rate rose from 2013 to 2017. In 2014, the enterprise's profit 
margin dropped significantly, but only recovered in 2015, especially in 2016 and 2017, the decline was about half of the previous year. Looking at the table above, we can see that the overall income of the enterprise has been rising in the past five years. But for the balance sheet, the balance sheet ratio has been stable. On the other hand, the existing resources of the enterprise will become tense. In the next five years, the sales revenue is decreasing, but the operating profit is not very stable. It can be inferred that Huawei Technologies will invest in new scientific and the technological research and development again.

By comparing the financial data from 2013 to 2017, we can see that Huawei Technologies has so strong development momentum. The sales revenue has increased year by year. The sales revenue in 2017 increased by nearly 364.6 billion yuan compared with that in 2013 , which is enough to illustrate Huawei Technologies' incentive measures. The balance sheet reflects the level of assets and liabilities as well as the degree of risk bearing of the enterprise, which is normally maintained at $50 \%-60 \%$. But when Huawei Technologies' asset liability ratio reaches more than $60 \%$, it faces huge risks, so it needs to use a lot of external funds. Considering from the side, it faces risks, and with external funds, it is likely that Huawei Technologies is facing the research and development of new technologies.

As we can see from the increase of $R \& D$ expenses, administrative expenses and receivables of Apple Inc., the speed of technology upgrading and the cooperation of Public Relations Department of Apple Inc. are quite perfect, so Apple Inc. has made great achievements today. Apple Inc.'s sales revenue is generally on the rise. Since 2001, the capital surrounding is slow, and the return on net assets is lower than last year. After 2015, the inventory war rate and total asset rotation rate have both declined. The yield of sperm acid also showed a downward trend. According to the analysis, after 2015, the collection war rate shows an upward trend. According to the analysis, the book rotation rate in 2016-2016-2017 is 3.02\% higher than that in the same period of 2015, with inventory recovery rate and total assets turning rate. The results show that $35.73 \%$ and $25.84 \%$ respectively, and the rotation rate of current assets. The financial performance of the enterprise was impacted timely. The impact is higher than the deposit recovery rate. The second is the company that pursues sales performance and neglects management.

Looking at the discount analysis chart again, Huawei Technologies' profit trend is to grow upward every year, and will be equal to Apple Inc.'s profit in 2017, which is enough to show that Huawei Technologies' performance management plays a very good role and Apple Inc.'s trend of maintaining its profit in recent years is to be stable.

\section{Case Analysis}

\subsection{Cause Analysis}

There is no reasonable standard, which is really a serious problem in performance evaluation. Because there is no fair and equitable standard, senior leaders do not know how to solve it, comment on the company's performance, and cannot assign specific work to subordinates, which results in the failure to finish the orderly work within the specified time ${ }^{[3]}$. But Huawei Technologies' actions in a series of systems have solved these problems and raised our performance level one level.

Team reflexivity includes cognitive reflexivity and emotional reflexivity. A team with a high degree of cognitive reflexivity can ensure team effectiveness and focus on coping with internal and external environment changes, detect the defects of the current action plan of the team, make team members work together better and form improvement plans, and constantly improve team members' average satisfaction, commitment level, information processing quality and team performance; emotional reflexivity is the team's handling of interpersonal relationships and strengthening Team work, enhance team members' happiness, satisfaction and team sustainable development ability, and improve team performance. The higher the cognitive reflexivity is, the more conducive it is to encourage team members to actively launch open reflexivity and discussion on the internal and external environment of the enterprise ${ }^{[4]}$, promote effective interaction among team members, 
deepen emotional communication and exchange among team members, promote emotional reflexivity, and reduce the possibility of emotional conflict among team members; emotional reflexivity can promote minority groups to dare to make different statements Opinions, showing the real ideas in the heart, not afraid of causing interpersonal tension, and this minority opinion is an important factor to promote the team's cognitive reflexive behavior. The evolution of the flexible of the senior management team of technology-based companies has a huge impact on electronic technology products ${ }^{[5]}$. The first stage is self reflection based on the trust of their teams. The second stage of Apple Inc. is developed because of the addition of new members and the impact of the new situation on Apple Inc.'s senior management self reflection. In the third stage, because of the increasing turbulence and conflicts, the top management companies have to make a light analysis, but they have no choice but to find new trends in performance decline. In the fourth stage, when the cognition reaches a certain level, the enterprise performance begins to rise gradually.

\subsection{Research Inspiration}

With the rapid development of science and technology, electronic products and high-tech products are updating rapidly. How does Huawei Technologies deal with such a fast-growing development and improve the performance of the company to complete the new stage of management? We use the balance of profit and loss pricing method and competitive price pricing method to compare the price and quality of companies to improve the performance. Although it's a good choice for the initial market to use the profit and loss balance pricing method, it's not limited to simple profit and loss balance for multinational companies like Huawei Technology ${ }^{[6]}$. The competitive price pricing method is the first choice currently, in order to maintain profit and loss balance and maximize profits.

\section{Conclusion}

The rapid growth of Huawei Technologies' and Apple Inc.'s performance is due to the R\&D resources and the optimized quality of resources. Due to the implementation of comprehensive incentive policies for the prediction, Huawei Technologies' product creation performance and marketing means have made significant breakthroughs. With the globalization and internationalization of science and technology, Huawei Technologies has opened up to foreign markets. Huawei Technologies has put forward the connotation of the idea of knowledge-based. The interest community and business community formed by high-tech companies under this idea can have strong cohesive effects in the enterprise. Huawei Technologies uses BSC to evaluate the performance management of $\mathrm{R} \& \mathrm{D}$ expenses of senior management companies, and Apple Inc. uses technology to drive companies to enhance their performance through self reflection ${ }^{[7]}$.

For channel marketing, Huawei Technologies needs to consider the public idea in addition to its own research and development and output of its own products. Through the investigation of the public, it can change the customer's satisfaction with its own products at any time, achieve constant modification, and maximize the satisfaction at the same time. The speed of Apple Inc.'s update has aroused the public's love for Apple Inc.'s products, thus making it more rapid. Develop the R\&D products, so as to promote the level of scientific and technological development of their own country.

Grey relation analysis is a method of factor comparison analysis. Its essence is the analysis of curve development and change. Its measurement scale is based on the gap between curves. First, determine its reference sequence. When the ideal object is not clear, the optimal value of each time point of all samples can be selected to form the ideal object. Secondly, standardize the data. It is convenient to standardize the reference data and related matters, and turn the original data into dimensionless, peer-to-peer, positive additive data. The third is to construct the optimal data and find out the optimal correlation data. 


\section{References}

[1] Xu Jieyu. Equity incentive, R \& D allocation and company performance. Zhengzhou Institute of aviation industry management, 2017.

[2] Tan binzhao. Intellectualism: business philosophy of high-tech companies -- from the practice of Huawei Technology Co., Ltd.. Science and technology progress and countermeasures, vol.11, pp.46-47, 2000.

[3] Lin Xuejun, Liang Yuan, Han Jiaxu, Xiao yefen. Study on industrial upgrading based on the double spiral model of global innovation chain and global value chain -- Taking Huawei as an example. International business research, vol.5, pp. 39-48,2018.

[4] Rong Pengfei, Ge Yuhui. Reflexive evolution and product innovation performance of senior management team in technology-based companies: Apple Inc. Case Study. China Science and Technology Forum, vol.9, pp.29-33, 2014.

[5] Bo Jiankui, Shang Qingdi, Sun Kang. Research on performance evaluation of R \& D expenses of high-tech companies based on BSC -- Taking Huawei Technologies as an example. Financial economy, vol.22, pp.68-69, 2017.

[6] Guan Chang. Research on the impact of working capital management on corporate financial performance -- Taking Apple Inc. as an example. Taxation, vol.9, pp.93, 2018.

[7] Wang Derong, Dong Jinquan. Performance evaluation of Apple Inc. concept stock listed companies based on grey relation analysis. China market, vol.12, pp.55-57, 2015. 